\title{
QUESTÕES DO DESENVOLVIMENTO RURAL: PERSPECTIVAS DE DINAMIZAÇÃO DO CAMPO A PARTIR DE ATIVIDADES NÃO AGRÍCOLAS NA REGIÃO DE JALES (SP) ${ }^{1}$
}

\author{
RURAL DEVELOPMENT ISSUES: PERSPECTIVES OF FIELD STIMULATION \\ FROM NON AGRICULTURAL ACTIVITIES IN THE REGION OF JALES (SP)
}

\author{
CUESTIONES DE DESARROLLO RURAL: PERSPECTIVAS DE LA \\ ESTIMULACIÓN DE CAMPO DE LAS ACTIVIDADES NO AGRÍCOLAS \\ DE LA REGIÓN DE JALES (SP)
}

\author{
Evandro César Clemente - Universidade Federal de Goiás - Jataí - Goiás - Brasil \\ evandroclemente@yahoo.com.br
}

Antonio Nivaldo Hespanhol - Universidade Estadual Paulista - Presidente Prudente - São Paulo - Brasil nivaldo@fct.unesp.br

\section{Resumo}

0 trabalho procura debater a possibilidade de dinamizar a economia da região de Jales a partir do desenvolvimento de atividades rurais não agrícolas, como o turismo rural, conforme preconizado por grande parte da literatura que trata do desenvolvimento rural. A região se caracteriza pelo predomínio de pequenas propriedades rurais, do trabalho familiar e da policultura, destacando-se a viticultura, a laranja e a pecuária leiteira. Porém, a região está distante de grandes centros urbanos e não conta com atrativos que possam alavancar a economia regional a partir do turismo rural e de outras atividades rurais não agrícolas.

Palavras-chave: desenvolvimento rural, atividades rurais não agrícolas, Jales, dinâmica econômica regional e pequenos proprietários rurais.

\begin{abstract}
The paper seeks to discuss the possibility of boosting the region's economy Jales from the development of rural non-farm activities, such as rural tourism, as advocated by much of the literature dealing with rural development. The region is characterized by the predominance of small farms, family work and polyculture, especially viticulture, orange and dairy farming. But the region is far from large urban centers and it doesn't have attractive to leverage the regional economy from tourism and other rural non-farm rural activities.

Keywords: rural development, rural non agricultural activities, Jales, dynamic regional economic and small landowners.

\section{Resumen}

El artículo trata de discutir la posibilidad de impulsar la economia de la región de Jales, desde el desarrollo de las zonas rurales lãs actividades no agrícolas, como el turismo rural, como se propone em gran parte de la literatura sobre el desarrollo rural. La región se caracteriza por el predomínio de pequeñas explotaciones agrícolas, mano de obra familiar y el policultivo, la viticultura em particular, las naranjas y la ganadería lechera. Pero la región está lejos de los grandes centros urbanos y no tiene atractivos que pueden aprovechar la economía regional a través del turismo rural y otras actividades no agrícolas rurales.
\end{abstract}

Palabras clave: desarrollo rural, actividades rurales no agrícolas, Jales, dinâmicas econômicas regional y labradores. 
Introdução

O trabalho analisa a questão da alavancagem do desenvolvimento ou da dinâmica econômica a partir de atividades rurais não agrícolas, discutidas com base na realidade apresentada pelo Escritório de Desenvolvimento Rural (EDR) de Jales, no noroeste paulista.

Neste sentido, o principal objetivo do trabalho foi caracterizar o EDR de Jales, em especial seu espaço rural, e debater a dinamização econômica deste à luz das teorias que embasam atualmente o desenvolvimento rural.

Para o desenvolvimento da pesquisa, realizou-se levantamento bibliográfico acerca do tema e foram coletados dados no sítio eletrônico da Fundação Sistema Estadual de Análise de Dados (SEADE) e do Instituto Brasileiro de Geografia e Estatística (IBGE).

\section{Caracterização da região de Jales}

O Escritório de Desenvolvimento Rural de Jales (EDR) localiza-se no noroeste paulista. É composto por 22 municípios: Aparecida d'Oeste, Aspásia, Dirce Reis, Dolcinópolis, Jales, Marinópolis, Mesópolis, Nova Canaã Paulista, Palmeira d'Oeste, Paranapuã, Pontalinda, Rubinéia, Santa Albertina, Santa Clara d’Oeste, Santa Fé do Sul, São Francisco, Santana da Ponte Pensa, Santa Rita d'Oeste, Santa Salete, Três Fronteiras, Urânia e Vitória Brasil.

O processo de ocupação da região ocorreu a partir do final dos anos 1930, sendo marcado por grilagens e especulação de terras, tanto por Companhias de Colonização, incluindo as estrangeiras, quanto por grileiros, que, por conta da crise de 1929, retalharam suas glebas e buscaram atrair migrantes das chamadas "Zonas Velhas" (áreas de ocupação mais antiga) interessados em adquirir um lote de terra. Isso deu origem a uma estrutura fundiária marcada por pequenas e médias propriedades rurais, que ainda hoje são predominantes (Nardoque, 2007).

A região de Jales se caracteriza como uma área tipicamente rural, sendo que a partir dos anos 1990, com a decadência da cafeicultura, a viticultura de mesa passou a ser o carro-chefe da agropecuária regional.

O setor secundário, apesar de existente, não se apresenta de maneira expressiva, e as atividades do setor, na maioria das vezes, encon- 
tram-se vinculadas às atividades agrícolas, como curtumes, frigoríficos, laticínios. Os 22 municípios que integram a região, em geral, são muito pequenos e dependentes de Jales em relação ao comércio e aos serviços. A atividade responsável diretamente pelo dinamismo regional é a agricultura, revelada pela significativa importância da fruticultura. Em menor grau, aparece a pecuária leiteira, responsável por gerar um fluxo regular de renda ao produtor rural (Clemente, 2006).
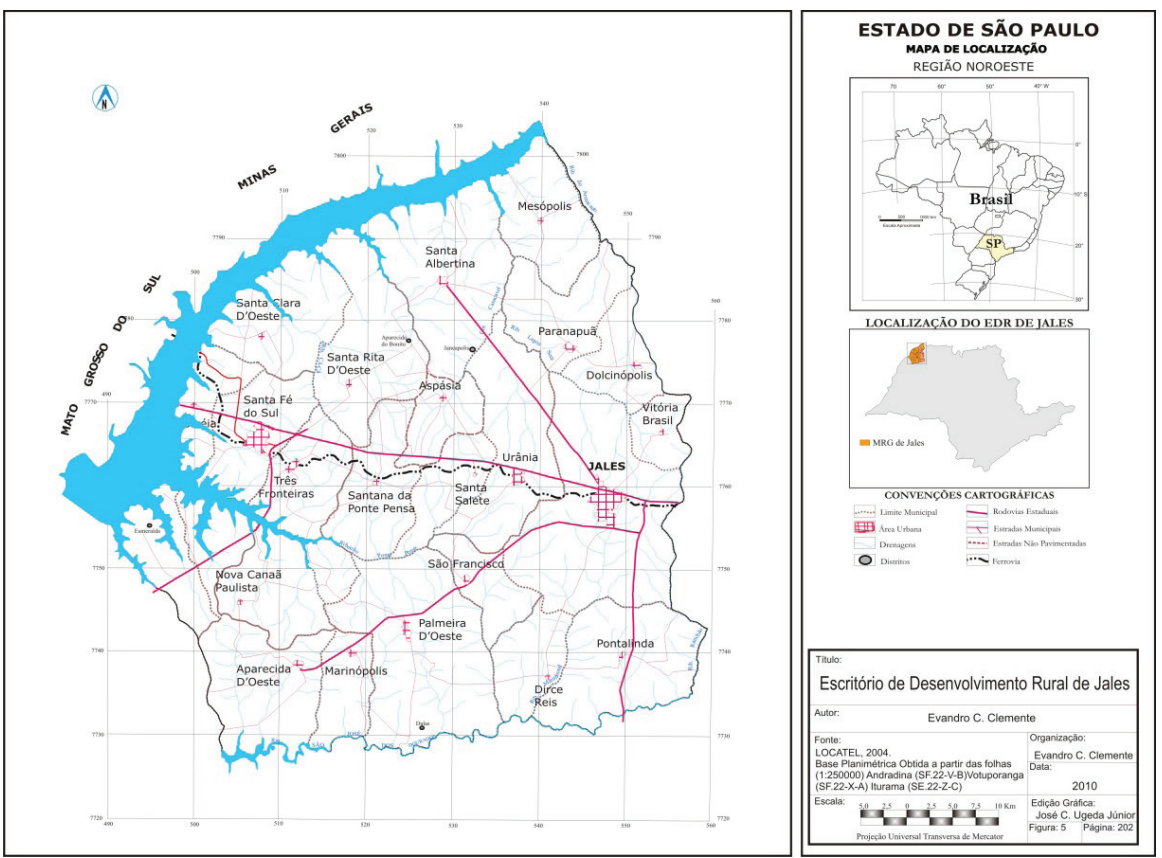

Figura 1 - Localização do Escritório de Desenvolvimento Rural de Jales (SP)

Há o predomínio de uma estrutura fundiária desconcentrada, que apresenta pequenos e médios estabelecimentos rurais perfazendo a maior parte dos estabelecimentos agropecuários, tanto em número quanto em área ocupada (Locatel, 2004; Clemente, 2006). Também prevalece o trabalho de base familiar (Carvalho; Khun, 2001) e a diversificação da produção agrícola. Assim, o dinamismo econômico dos incipientes centros urbanos depende necessariamente do desempenho das atividades agropecuárias. 
Nardoque (2007) ressalta a importância das atividades agropecuárias na referida região:

Em Santa Fé do Sul e Rubineia o turismo apresentou expansão nos últimos anos, principalmente com a transformação da primeira em Estância Turística. Em Jales, principal cidade da MRG, o setor de serviços é o mais importante, correspondendo a $47,9 \%$ do PIB do município, resultante da concentração de atividades no setor público como também no privado. Nos demais, percebe-se nitidamente a importância da agropecuária na composição da economia. O valor adicionado pela indústria não é expressivo na região, somente com destaque para Jales, que possui $54,9 \%$ do valor total da indústria regional. (Nardoque, 2007, p. 274)

A região é constituída por municípios de pequeno porte e distantes de grandes centros urbanos, daí a dificuldade de dinamizar a sua economia por meio do desenvolvimento de atividades rurais não agrícolas, já que não há população concentrada em grandes centros urbanos com renda e disposta a consumir as amenidades do rural, como paisagens, gastronomia, tradições etc., como ocorre em áreas situadas nas proximidades de grandes cidades e/ou com potencial turístico. Neste sentido, até existem atividades rurais não agrícolas na região, como pesque-pagues e hotéis, porém são pouco expressivas e não se apresentam com fôlego para dinamizar a economia local. Além se estar situada distante dos grandes centros, a região não conta com atrativos turísticos capazes de despertar grande interesse e atenção de pessoas que não residem ali.

Tendo em vista a realidade do espaço rural da região de Jales, buscaremos analisar a questão da dinamização econômica a partir das propostas apresentadas sobre o desenvolvimento rural.

\section{A questão do desenvolvimento rural na região de Jales}

A concepção de desenvolvimento territorial passou a servir de base para as políticas públicas direcionadas ao campo brasileiro a partir dos anos 1990. Dentre os fatores externos que concorreram para tanto se destacam: a) o sucesso dos programas e projetos de desenvolvimento rural na Europa, como o Programa Ligações entre Ações de Desenvolvimento da Economia Rural (LEADER); b) o estímulo e pressão de organismos internacionais (sobretudo do Banco Mundial); c) os questionamentos de caráter ambiental frente ao modelo predatório estabelecido a partir da implemen- 
tação do pacote tecnológico da Revolução Verde; d) declínio da importância das atividades agrícolas e o crescimento das atividades não agrícolas; e) revitalização das áreas rurais com as "migrações de retorno"; f) avanço do neoliberalismo com a "diminuição" do Estado, a descentralização da gestão das políticas públicas.

Na base de todos esses processos, devemos apontar o avanço da globalização e do neoliberalismo, que também tem levado a uma redefinição do papel do Estado. Este, cada vez mais, procura implementar políticas que têm como diretrizes a descentralização administrativa e a busca da participação dos agentes locais (Veiga, 2002; Abramovay, 2000; Schneider, Tartaruga, 2004; Favareto, 2007).

Todos esses fatores, em menor ou maior grau, concorrem para a adoção do discurso do desenvolvimento territorial no Brasil pelos órgãos governamentais. Porém, na prática, as ações têm sido tímidas e pontuais, de modo que as propostas tidas como "inovadoras" têm se limitado ao discurso. De acordo com Favareto (2007), isso ocorre porque as instituições que deveriam coordenar as ações com base no formato territorial, ainda permanecem vinculadas ao formato antigo das políticas públicas, ou seja, setoriais e produtivistas.

Com a nova abordagem sobre o rural, o campo, que antes era tido como sinônimo de problema, sempre associado a isolamento e pobreza, agora passou a ser encarado como portador de soluções, dada a possibilidade de geração de emprego e renda nesse espaço (Wanderley, 2001). Nessa mesma linha argumentativa, Abramovay (2000) enfatiza que não é mais possível associar o rural ao atraso, à precariedade, à pobreza e à falta de infraestrutura, pois muitas das regiões dinâmicas economicamente nos países desenvolvidos são rurais, e muitos dos melhores índices de desenvolvimento humano (IDH) advêm de áreas tipicamente rurais.

Em texto apresentando os resultados dos Projetos Rurbano I e II, Silva, Del Grossi, Campanhola (2002) demonstram que, por um lado, no Brasil tem ocorrido um declínio muito forte do número de famílias e de trabalhadores dedicados exclusivamente às atividades agrícolas, crescendo, por outro lado, as ocupações não agrícolas. Ao mesmo tempo, também cresce o número de aposentados no meio rural.

O caráter inovador do desenvolvimento rural está em reconhecer o caráter multifuncional e multidimensional do espaço rural, pois ele abriga atividades agrícolas e não agrícolas e se constitui em espaço privilegiado para proteger os recursos naturais. 
Tradicionalmente, o meio rural caracterizou-se por apresentar menor dinamismo econômico que as áreas urbanas e, como consequência, maiores índices de pobreza. Isso porque as atividades agropecuárias sempre se mostraram menos dinâmicas e mais vulneráveis, tendo em vista as intempéries naturais, o fato de lidar com seres vivos e depender do ciclo biológico das plantas e animais, de ter a oferta concentrada no tempo e pulverizada entre muitos produtores e de, normalmente, haver poucos compradores para os alimentos e matérias-primas produzidos.

Até recentemente, houve o predomínio de uma visão dualista e estática que tinha o rural como sinônimo de agrícola, e o urbano, de industrial. O intenso processo de industrialização e de urbanização e a magnitude do acentuado êxodo rural redundaram num esvaziamento do campo e na desvalorização deste. A forte urbanização fez crescer as distinções/polarizações entre o rural e o urbano, chegando a situá-los como opostos, com o urbano sendo associado ao moderno, industrial, rico, e o campo, ao atrasado, pobre.

Dessa forma, cada vez mais, as análises passaram a ser dicotômicas, situando e associando o desenvolvimento ou a dinamização econômica como privilégio apenas de regiões urbanizadas, ficando as áreas rurais identificadas com a pobreza e o esvaziamento populacional. O desenvolvimento das áreas rurais, por hipótese, somente se tornaria possível se estas sofressem um processo de urbanização, de maneira que essas análises sempre conceberam a ruralidade como elemento de uma formação social anterior ao capitalismo, que tenderia assim a desaparecer à medida que este se aprofundasse (Veiga, 2002).

Com a recuperação do dinamismo econômico de algumas áreas rurais nos países desenvolvidos, essa ideia do rural como "residual" entrou em xeque, pois, como explicar o forte dinamismo econômico de áreas tipicamente rurais que não se tornaram necessariamente urbanas?

Atividades econômicas vinculadas aos setores secundário e terciário, antes quase que exclusivas do urbano, têm se instalado no campo, como indústrias, moradias, hotéis, pousadas, pesque-pagues, restaurantes, turismo e lazer rural. Portanto, o rural já não é um lócus somente de atividades agrícolas. Por conta disso, emergiram questões ligadas ao problema, cada vez maior, da definição e delimitação do rural, que, de certo modo, foi superado a partir da adoção de políticas territoriais (Saraceno, 1996). Deste modo, um grande avanço do paradigma territorial foi o de 
considerar o campo como local de atividades diversificadas que não se restringem apenas ao ramo agrícola.

Campanhola e Graziano da Silva (2000) salientam que os limites geográficos entre o rural e o urbano deixaram de ter importância:

Hoje, uma divisão clara entre rural e urbano deixou de ser importante, pois as relações de troca se diversificaram, e o enfoque passou a ser nos espaços (territórios) que dão suporte físico aos fluxos econômicos e sociais, relegando a um plano inferior a preocupação com os seus limites geográficos. Essa mudança tem consequências relevantes na definição de políticas públicas, pois passa-se a priorizar a dinâmica dos processos e fluxos econômicos em detrimento da abordagem anterior, em que se consideravam divisões estanques entre as atividades urbanas e as rurais. (Campanhola; Graziano da Silva, 2000, p.12)

A adoção do conceito de território permitiu que o espaço rural fosse considerado a partir da sua multifuncionalidade, abrigando atividades agrícolas, indústrias, lazer, turismo e aproveitando as suas amenidades, que agora são "valorizadas" como mercadorias a serem consumidas.

Compreendemos que a abordagem territorial permite uma análise holística da realidade, possibilitando superar não apenas a clivagem rural/ urbano, como também a dicotomia sociedade/natureza, o que se reveste de significativa importância, à medida que a crise ecológica no mundo tem se acirrado com a ampliação dos problemas ambientais, atualmente, incluindo o rural. Isso permite pensar de modo integrado as questões da esfera socioeconômica com a dinâmica natural, imprescindível para minimizar os efeitos ambientais negativos e adequar/equilibrar as relações sociedade/natureza.

Parte da literatura considera que, com o aprofundamento da tecnificação dos processos produtivos agrícolas, resultando em maior produtividade e menores custos, a agricultura, de modo geral, vem se revelando como um setor que apresenta a tendência, cada vez menor, de gerar empregos e renda para os pequenos proprietários rurais, em virtude do aumento da produtividade, que tende a requerer menos mão de obra. Diante disso, cada vez mais, esses pequenos proprietários tendem a depender de políticas públicas e do êxito de empreendimentos não agrícolas no meio rural, como pesque-pagues, hotéis-fazenda, pousadas; também, buscam emprego ou realizam alguma atividade produtiva nas cidades, caracteri- 
zando, assim, a pluriatividade e a agricultura de tempo parcial (part time farming).

Contudo, pensamos que hoje, como a indústria já não tem grande capacidade em gerar postos de trabalho, o apoio à agricultura familiar cada vez mais se torna importante, pois é um setor que tem potencial para gerar um significativo número de empregos, em especial nos municípios de pequeno porte.

Santos (2008 [1988]) ressalta que, neste período de mundialização do capital, todos os lugares foram atingidos de maneira direta ou indireta pelas necessidades do processo produtivo capitalista, havendo, assim, uma reorganização das funções no território, cuja relevância de cada ponto do espaço decorre de suas próprias virtualidades, sejam elas naturais ou sociais, preexistentes ou adquiridas.

Com a mundialização e o crescimento e expansão das empresas globais, observa-se uma tendência para a contínua busca de lugares mais rentáveis ao capital. Dessa forma, muitos recursos naturais e amenidades que antes não eram valorizados agora são considerados cruciais para garantir o dinamismo de algumas áreas rurais, como a beleza das paisagens, o "ar puro", o lazer e o turismo no campo, o patrimônio cultural local e ambiental. As empresas capitalistas estão sempre em busca de novos espaços de valorização e maior rentabilidade. Assim, é compreensível que, com o atual desenvolvimento das forças produtivas e o maior desenvolvimento dos sistemas de transporte e de comunicações, possibilitou-se o acesso, a articulação de lugares longínquos, fazendo com que os espaços rurais assumam funções e atividades anteriormente tidas como exclusivas dos espaços urbanos, como a indústria, moradia, setores de serviços de turismo e lazer.

Os baixos preços de imóveis nas áreas rurais, para a implantação de empreendimento de turismo e lazer, condomínios, áreas residenciais, constituem um forte atrativo, frente à relativa baixa rentabilidade auferida pelos produtos agrícolas tradicionais e aos altos preços imobiliários praticados nos mercados urbanos. Projetos viabilizados pela expansão da rede de estradas, que, por sua vez, asseguram uma mobilidade espacial mais rápida e barata.

Em algumas abordagens sobre o desenvolvimento rural, existe a crença de que a dinamização das áreas rurais depende somente da sua capacidade de atrair atividades de serviços, lazer e turismo rural. O re- 
conhecimento da relevância de atividades não agrícolas representa um avanço teórico-metodológico importante, porém é necessário estar atento para a heterogeneidade da realidade, como no caso brasileiro, em que, ainda, em muitas regiões, a dinâmica econômica dos municípios é fortemente dependente das atividades agrícolas. Assim, não se pode perder de vista a relevância dessas atividades, visto que, apesar do declínio de sua importância econômica, constituem um setor estratégico, pois é a base da segurança alimentar do país e a garantia de renda para muitos pequenos proprietários rurais e trabalhadores do campo.

Compreendemos as mudanças que vêm sendo operadas no rural e no urbano, atualmente, como derivadas do processo de equalização e diferenciação do capital no espaço (Smith, 1990). A instalação de serviços e de atividades industriais no campo e o aproveitamento de elementos/ recursos que antes não tinham valor econômico derivam desse processo de equalização/homogeneização do capital, na sua busca constante de transformar tudo em mercadoria e de "alargar", expandir as condições para a sua reprodução, nos mais variados recantos do globo, impondo e aprofundando a sua lógica.

O capital precisa de condições adequadas para se afirmar como capital em geral, como universal concreto, que comanda todo o processo social de trabalho, necessitando de um espaço unificado, homogeneizado e desobstruído, em que possa exercer seu controle universalizante, invadindo todos os âmbitos possíveis da sociabilidade, extravasando sua lógica sem circunscrições territoriais. (...) Esse processo homogeneizador deve ser encarado através do vetor da acumulação capitalista de busca de valorização unificada e da universalização da mercadoria. (Brandão, 2007, p. 73)

A homogeneização, em que tudo tende a se transformar em mercadoria, é acompanhada, contraditoriamente, de processos de diferenciação, fazendo com que os espaços tenham níveis distintos de desenvolvimento e integração efetiva ao mercado. Por um lado, no processo de equalização/homogeneização, os agentes hegemônicos do capitalismo buscam expandir e dotar todos os espaços com as condições necessárias para o seu desenvolvimento e reprodução. Por outro lado, nem todos os espaços são atingidos de maneira homogênea pela expansão do capital, que, paradoxalmente, se nutre das desigualdades espaciais, recriando as desigualdades regionais pela expansão do progresso técnico, de maneira assimétrica, 
no espaço, e, consequentemente, gerando desigualdades e assimetrias no desenvolvimento.

O rural não apresenta estas mudanças - presença de atividades não agrícolas - impactando as diferentes áreas de maneira homogênea, sobretudo numa realidade de um país subdesenvolvido como o Brasil que se insere na divisão internacional do trabalho, exportando majoritariamente produtos primários, em que há grande relevância das atividades agrícolas.

Cremos que considerar a dinamização econômica do rural apenas pela sua capacidade de atrair atividades ligadas à indústria e aos serviços não contempla a proposta do desenvolvimento territorial, pois acaba por supervalorizar os setores secundário e terciário, em detrimento do primário. Se nos libertarmos da racionalidade estritamente econômica e engendrarmos também as questões ambientais e a problemática da segurança alimentar da população brasileira, verificaremos que o agrícola ainda possui muita relevância, especialmente para os pequenos proprietários rurais do interior do país.

O peso das atividades agrícolas é muito forte no Brasil, quando comparado à maioria dos países industrializados/desenvolvidos. Tanto que no interior do país têm ocorrido o surgimento e o crescimento de centros urbanos que funcionam como "ponto de apoio" de comércio e serviços (suporte) para as atividades agrícolas "modernas" e globalizadas (agronegócio) que ocorrem ali e que garantem a dinamicidade econômica do local, incluindo a urbana, conforme demonstra Elias (2007).

Outra mudança de destaque no meio rural é a crescente preocupação da sociedade com os problemas ambientais na agricultura. Têm surgido correntes como a da agroecologia, os cultivos orgânicos (sem utilização de agrotóxicos), a preocupação com as paisagens rurais etc. Assim, têm emergido novos mercados, de maneira a inserir produtos, cultivos, amenidades, paisagens, elementos que, anteriormente, não eram valorizados como mercadorias, no campo, pelo paradigma desenvolvimentista (era da Revolução Verde). Assim, elementos que anteriormente tinham apenas valores de uso passaram a ter valor de troca e se transformaram em mercadorias (Van Der Ploeg et al., 2000).

Seguindo esta tendência é que encontramos explicação para os processos de industrialização e urbanização difusas a partir dos anos 2000, que são responsáveis, em grande parte, pela revitalização econômica de áreas rurais no interior do país, o que tem contribuído para estancar o 
êxodo rural e até, em alguns casos, revertê-lo, numa proporção bem menor, é claro, com a chamada "migração de retorno".

Porém, a expansão dos setores secundário e terciário, no campo, não ocorreu de forma homogênea, mas, sim, desigualmente, de maneira que alguns espaços foram dinamizados economicamente a partir da geração de emprego e renda, enquanto que, em parcelas consideráveis dos espaços rurais, as atividades não agrícolas não se desenvolveram de maneira expressiva, permanecendo esses espaços deprimidos economicamente ou tendo sua riqueza gerada pelo agronegócio.

A indústria passou a deslocar-se para áreas rurais do interior, seguindo o processo de desconcentração industrial motivado pelas deseconomias de aglomeração dos grandes centros urbanos - os incômodos dos congestionamentos, os diversos tipos de poluição, os altos preços dos imóveis, a maior organização sindical dos trabalhadores, a violência e criminalidade -, gerando a denominada industrialização difusa.

Todos esses processos de industrialização e urbanização difusas e a revalorização do rural vêm acontecendo, paradoxalmente, por conta da acelerada urbanização e metropolização ocorridas durante o século XX. Isso gerou uma deterioração crescente das condições de vida nas cidades, resultando em prejuízos à saúde física e mental de seus habitantes. Somadas a isso, têm-se a robotização e a terceirização das atividades produtivas, que são responsáveis pelo aumento do desemprego e da precarização das relações de trabalho no meio urbano, contribuindo para as migrações de retorno.

Lembra-nos Veiga (2002) que, diante do amplo predomínio da urbanização, emerge uma revalorização do rural; no entanto, um rural transformado, modificado.

A tendência de redução da renda gerada pelas atividades agrícolas deve ser compensada pelo Estado, via políticas públicas que contemplem as necessidades dos pequenos proprietários rurais, visando a garantir a reprodução social e a permanência destes no campo. Um passo importante nesse sentido seria a adoção de políticas públicas efetivamente territoriais, que englobassem a dimensão produtiva agrícola, ambiental, cultural, bem como as atividades não agrícolas, adequando-as de acordo com as características e necessidades dos distintos territórios.

Tendo em vista tais transformações, procuraremos desdobrar o debate tendo como recorte espacial o Escritório de Desenvolvimento Rural 
(EDR) do município de Jales, levando em conta as suas particularidades, como estrutura fundiária desconcentrada, predomínio do trabalho familiar e a policultura. A seguir, apresentaremos uma caracterização sucinta do espaço rural da região e colocaremos em questão a capacidade das atividades rurais não agrícolas em alavancar a dinamização econômica da referida área.

Silva, Del Grossi, Campanhola (2002) argumentam, através da apresentação e análise de dados da Pesquisa Nacional por Amostra de Domicílios (PNAD), que a população rural no Brasil, nos anos 1990, voltou a crescer, ao passo que a população economicamente ativa na agricultura (PEA agrícola) continua apresentando declínio na absorção dessa mão de obra. O que tem sustentando esse aumento da população rural no campo brasileiro é a expansão das ocupações rurais não agrícolas (ORNAs) e também, não podemos negar, a implantação de assentamentos rurais em algumas regiões do país.

É inegável que as atividades não agrícolas vêm ganhando importância no rural brasileiro, porém, em face dessas conclusões dos referidos autores, nos posicionamos de maneira cautelosa quanto a esta forte perda de importância da agricultura no meio rural e a expansão de novas atividades no campo brasileiro, por dois motivos: 1) a expansão das atividades não agrícolas, por sua própria natureza e característica, tem maior propensão de se desenvolver em áreas rurais próximas de regiões densamente urbanizadas e naquelas de alto potencial turístico; 2) há dubiedades em relação à veracidade e confiabilidade dos dados, por conta das questões envolvendo a delimitação de rural e urbano pelo IBGE.

A região de Jales possui população reduzida e distribuída em pequenos municípios distantes de grandes centros urbanos, com uma economia muito dependente das atividades agrícolas, já que ali também não existe potencial turístico com capacidade para atrair grandes contingentes de turistas e dinamizar a economia regional. Apesar de existentes, as atividades rurais não agrícolas não se apresentam de modo expressivo e com fôlego para dinamizar a economia regional a partir delas.

A importância das atividades secundárias e terciárias no campo tem crescido, de maneira geral, por elas garantirem maior retorno econômico a uma velocidade muito superior à rentabilidade dos ciclos dos processos agrícolas. Porém, por diversas questões, inclusive de renda, segurança alimentar, crise ecológica, entendemos que não se deve minimizar/descartar a relevância das atividades agrícolas. 
Sob a abordagem territorial, é imprescindível que a dinâmica do espaço rural seja compreendida e analisada de forma integrada à rede urbana, atentando para as diferentes funções desempenhadas pelas cidades. No caso da região em apreço, verifica-se que as cidades são de pequeno porte e com baixa expressividade do setor industrial.

Recentemente, houve a instalação de uma usina de álcool e açúcar no município de Santa Albertina (a Colombo III) e de outras unidades em municípios próximos da região de Jales, o que vem contribuindo para o incremento das plantações de cana-de-açúcar. Consequentemente, há a possibilidade de haver maior expansão do setor no contexto regional e isso vir a contribuir para elevar o emprego industrial no campo.

As atividades de turismo e lazer vêm adquirindo certo fôlego nos municípios margeados pelos rios Grande e Paraná, como Santa Fé do Sul, Santa Clara d'Oeste, Rubinéia, Santa Albertina e Mesópolis. Nas margens desses rios foram construídos os chamados "ranchos" ou "segunda residência”. Isso tem atraído turistas e pessoas interessadas no lazer, porém os efeitos socioeconômicos resultantes de tais atividades acabam ficando circunscritos apenas aos respectivos municípios, não tendo condições assim para alavancar a economia regional.

Verifica-se, na Tabela 1, que o setor agropecuário na região de Jales, apesar de contribuir com a menor parcela da economia regional, ainda apresenta significativo peso, com 12,27\% do valor adicionado, enquanto que a indústria e os serviços participam com $24,03 \%$ e $63,70 \%$, respectivamente. Contudo, quando se compara a agricultura regional com a relevância que a agropecuária possui no âmbito do Estado, com apenas 1,62\% do valor adicionado total, observa-se que o setor primário regional adquire uma dimensão muito mais significativa no contexto regional.

O setor agropecuário regional reveste-se de maior relevância ainda quando consideramos os menores municípios, como: Aparecida d'Oeste (29,53\%), Aspásia (32,54\%), Dolcinópolis (19,04\%), Marinópolis (31,52\%), Mesópolis (37,16\%), Nova Canaã Paulista (38,19\%), Palmeira d' Oeste (29,20\%), Paranapuã (24,21\%), Pontalinda (34,32\%), Rubinéia (28,92\%), Santa Albertina (21,59\%), Santa Clara d'Oeste (20,42\%), Santa Salete (32,28\%), Santana da Ponte Pensa (31,41\%), São Francisco (28,14\%), Três Fronteiras (21,21\%), Urânia (18,18\%) e Vitória Brasil (23,78\%). Entre os municípios indicados anteriormente, observa-se claramente que o setor 
agropecuário é mais importante que a indústria, porém menos relevante que o setor terciário.

Tabela 1 - Valor adicionado por setor da economia nos municípios da região de Jales (SP)

\begin{tabular}{|c|c|c|c|c|c|c|}
\hline Municípios & $\begin{array}{c}\text { Agropecuária } \\
\text { (\%) }\end{array}$ & $\begin{array}{c}\text { Indústria } \\
(\%)\end{array}$ & $\begin{array}{c}\text { Serviços } \\
(\%)\end{array}$ & $\begin{array}{c}\text { Total } \\
(\%)\end{array}$ & $\begin{array}{c}\text { PIB total do } \\
\text { município } \\
\text { (milhões de } \\
\text { reais) }\end{array}$ & $\begin{array}{c}\text { Renda } \\
\text { per } \\
\text { capita } \\
(\mathrm{R} \$)\end{array}$ \\
\hline Aparecida d'Oeste & 29,53 & 9,79 & 60,69 & 100 & 46,59 & $10.132,72$ \\
\hline Aspásia & 32,54 & 7,42 & 60,04 & 100 & 18,54 & $10.155,43$ \\
\hline Dirce Reis & 19,39 & 30,27 & 50,34 & 100 & 24,41 & $15.037,21$ \\
\hline Dolcinópolis & 19,04 & 10,02 & 70,94 & 100 & 21,80 & $9.593,40$ \\
\hline Jales & 4,19 & 22,58 & 73,23 & 100 & 668,45 & $13.370,17$ \\
\hline Marinópolis & 31,52 & 13,13 & 55,35 & 100 & 26,66 & $12.353,81$ \\
\hline Mesópolis & 37,16 & 18,41 & 44,43 & 100 & 37,26 & $21.088,45$ \\
\hline $\begin{array}{l}\text { Nova Canaã } \\
\text { Paulista }\end{array}$ & 38,19 & 14,91 & 46,90 & 100 & 29,42 & $13.547,37$ \\
\hline Palmeira d'Oeste & 29,20 & 7,36 & 63,44 & 100 & 108,12 & $11.139,11$ \\
\hline Paranapuã & 24,21 & 14,90 & 60,90 & 100 & 45,14 & $12.073,37$ \\
\hline Pontalinda & 34,32 & 9,58 & 56,10 & 100 & 38,30 & $9.119,59$ \\
\hline Rubinéia & 28,92 & 8,97 & 62,11 & 100 & 32,48 & $12.439,71$ \\
\hline Santa Albertina & 21,59 & 11,17 & 67,23 & 100 & 56,41 & $11.300,76$ \\
\hline Santa Clara d'Oeste & 20,42 & 9,59 & 69,99 & 100 & 22,00 & $10.274,91$ \\
\hline Santa Fé do Sul & 1,51 & 41,71 & 56,79 & 100 & 559,73 & $19.174,26$ \\
\hline Santa Rita d' Oeste & 22,52 & 26,38 & 51,10 & 100 & 39,32 & $15.721,62$ \\
\hline Santa Salete & 32,28 & 14,96 & 52,77 & 100 & 24,23 & $16.754,63$ \\
\hline $\begin{array}{l}\text { Santana da Ponte } \\
\text { Pensa }\end{array}$ & 31,41 & 7,04 & 61,55 & 100 & 19,32 & $11.953,83$ \\
\hline São Francisco & 28,14 & 10,94 & 60,92 & 100 & 26,44 & $9.137,01$ \\
\hline Três Fronteiras & 21,21 & 12,96 & 65,83 & 100 & 49,73 & $9.631,43$ \\
\hline Urânia & 18,18 & 14,93 & 66,88 & 100 & 87,49 & $9.713,89$ \\
\hline Vitória Brasil & 23,78 & 13,03 & 63,18 & 100 & 17,45 & $10.497,53$ \\
\hline $\begin{array}{l}\text { Região de Jales } \\
\text { (EDR) }\end{array}$ & 12,27 & 24,03 & 63,70 & 100 & $1.999,30$ & $13.574,36$ \\
\hline $\begin{array}{l}\text { Estado de São } \\
\text { Paulo }\end{array}$ & 1,62 & 29,04 & 69,34 & 100 & $1.084 .353,49$ & $26.202,22$ \\
\hline
\end{tabular}

Fontes: Fundação Sistema Estadual de Análise de Dados (SEADE), 2011. www.seade.gov.br

Fundação Instituto Brasileiro de Geografia e Estatística (IBGE). Disponível em: www.ibge.gov.br. Acesso em: 6 jan. 2012. Org. Evandro César Clemente

Deste modo, se excluirmos o município de Jales - que é o maior da região e que exerce forte centralidade sobre os demais (Nardoque, 2007) 
- e o de Santa Fé do Sul (Estância Turística) - que se destaca no setor terciário pela relativa importância do turismo -, constatamos que a agropecuária perfaz 27,17\%, a indústria apenas $13,28 \%$, o comércio e os serviços respondem por 59,53\% do valor adicionado da economia regional. Isso corrobora o fato de que os pequenos municípios possuem uma dinâmica econômica fortemente dependente das atividades agropecuárias. Portanto, é evidente a relevância do setor agropecuário na região de Jales.

Advindo da proposição/vertente "neoliberal" do desenvolvimento territorial, em que o lugar "pode tudo", observa-se a proliferação de muitos estudos e artigos científicos defendendo o ecoturismo, o turismo rural, o lazer, o agroturismo como panaceia de maneira indiscriminada para o desenvolvimento de regiões deprimidas economicamente, visando assim a promover a dinamização econômica destas. Nessa literatura pós-fordista ou pós-industrial, muito influenciada pelo desempenho da "Terceira Itália”, Brandão (2007, p. 49-50) demonstra que existe "uma crença, subjacente ou explícita, de que o terciário pode ser facilmente replicável, em qualquer lugar, dependendo da vontade do poder público, mas sobretudo da iniciativa privada local”.

Guanziroli (2008) aponta que, no Brasil, as atividades não agrícolas, apesar da crescente relevância que adquirem, ainda são muito incipientes, ao passo que, por outro lado, a agricultura ainda conserva um papel importante no desenvolvimento rural.

Embora seja verdade que a agricultura não é a única atividade com capacidade de dinamizar os territórios, corre-se o risco de cair no outro extremo, e acabar minimizando o papel desta atividade em função de uma amplitude de setores que muitas vezes inexiste. (Guanziroli, 2008, p.10)

Reiteramos que a definição do peso das atividades na dinamização econômica de cada território não deve ser feita, a priori, por estudiosos ou formuladores de políticas públicas, mas sim a partir da realidade geográfica apresentada em cada território. "A complexidade e a multimensionalidade do desenvolvimento se associam, portanto, à heterogeneidade imposta pelas dotações geográficas e pela ocupação e evolução histórica do território" (Kageyama, 2008, p. 11).

Assim como Guanziroli (2008), Kageyama (2008) ratifica a significativa relevância que o agrícola ainda possui no país. "No Brasil, agricultura continua, sem dúvida, a ser a principal atividade do meio rural e, 
por conseguinte, não pode ser desprezada na análise do desenvolvimento rural” (Kageyama, 2008, p. 69). A autora chama a atenção para o fato de que é importante, hoje, a diversificação das fontes de renda dos agricultores, porém sem substituir a atividade agrícola, mas contribuindo para viabilizá-la.

Analisando a realidade do Estado de Pernambuco, Wanderley (2001) também constatou uma grande quantidade de pequenos municípios que possuem menos de 20.000 habitantes, sendo, portanto, bastante expressiva a presença rural nesses municípios, que dependem fortemente da renda gerada pelas atividades agropecuárias.

Há que se realizar um exame cuidadoso no contexto regional, e não partir de uma situação idealizada em consonância com a realidade rural dos países centrais e de restritas porções rurais brasileiras situadas nas proximidades de grandes centros urbanos, em que a dinamicidade dessas áreas advém de atividades não agrícolas, como lazer, recreação, residência, turismo rural, e cada vez menos das atividades agrícolas.

Consideramos, portanto, que o grande desafio para a promoção do desenvolvimento rural da região de Jales passa pela dinamização das atividades agropecuárias em pequenas propriedades. Para tanto, devem ser implementadas políticas com o intuito de ampliar a renda dos pequenos proprietários rurais, por meio da sofisticação dos canais de comercialização e agregação de valor. O intuito é aumentar a renda e reduzir a pobreza rural, dinamizando assim a economia regional, pois a melhoria da agropecuária tem efeitos diretos sobre o comércio e os serviços da região.

Em relação à segunda questão por nós levantada - sobre a veracidade e confiabilidade dos dados do IBGE -, há certa dubiedade em relação às metodologias utilizadas pelo Instituto Brasileiro de Geografia e Estatística, para a coleta e para o levantamento de dados apresentados pela Pesquisa Nacional por Amostra de Domicílios (PNAD). De acordo com Oliveira (2003), a metodologia apresenta problemas referentes aos limites normativos entre rural e urbano, em que muitos dados podem estar "contaminados” pela presença de áreas urbanas "clandestinas":

Assim, é preciso ponderar que a amostragem das estatísticas da PNAD está contaminada pela presença de grande número de amostras que caíram no urbano "clandestino" computado como rural. Portanto, não são só as estatísticas que registram um Brasil majoritariamente urbano, mas há, de fato, em todas as partes deste país continente, o modo de vida urbano dominando simultânea e con- 
traditoriamente a cidade e o campo. É possível que tenha faltado a necessária compreensão de que não são os dados que determinam a realidade, mas, ao contrário, é a realidade que determina os dados. (Oliveira, 2003, p. 50)

Silva, Del Grossi, Campanhola (2002) afirmam ainda que o emprego doméstico e a construção civil são os segmentos que mais empregam neste "novo rural brasileiro". Ora, tais ocupações, de baixa qualificação e remuneração, são típicas de áreas periféricas urbanas brasileiras, o que reforça a observação de Oliveira.

É importante ressaltar também que existe um alto dinamismo econômico das grandes propriedades rurais no Brasil, integrando o chamado "agronegócio". Geram riqueza e divisas no setor agrícola e contrastam, portanto, com um conjunto significativo de pequenas propriedades rurais que não apresentam o mesmo êxito econômico. Isso se deve aos modelos de políticas públicas para o campo, que sempre privilegiaram os grandes proprietários em detrimento dos pequenos. Estes, historicamente, sempre foram marginalizados pelas políticas direcionadas à agricultura.

A partir dos anos 1990 foram implementadas políticas públicas que despendem tratamento diferenciado aos pequenos proprietários rurais, como o Programa Nacional de Fortalecimento da Agricultura Familiar (PRONAF), os Territórios Rurais, os Territórios da Cidadania, o Programa de Aquisição de Alimentos (PAA). A abordagem territorial, se aprimorada, pode vir a ser uma importante via para valorizar a pequena propriedade, contemplando a multidimensionalidade do campo, substituindo as políticas dominantes que focalizam apenas a dimensão econômica, a exemplo do que ocorre com aquelas que estimulam a expansão do agronegócio brasileiro.

\section{Considerações finais}

As propostas de políticas públicas sob as diretrizes do desenvolvimento rural no interior do Brasil devem levar em conta a heterogeneidade que os distintos espaços rurais apresentam. Na realidade da região de Jales, a renda agrícola ainda é significativa em virtude da fraca expansão das atividades rurais não agrícolas.

Assim, a incipiente expansão das atividades rurais não agrícolas na região de Jales exige um repensar das estratégias para a promoção de seu 
desenvolvimento rural. É preciso valorizar a dinamização da economia regional a partir do fomento às atividades agrícolas, pois a região está situada distante de grandes centros urbanos e não possui significativos atrativos turísticos. As atividades de lazer e turismo desenvolvidas nos municípios ocorrem de modo mais pronunciado somente naqueles que são banhados pelos rios Grande e Paraná.

É importante salientar que as atividades rurais não agrícolas podem experimentar significativo crescimento a partir da expansão das usinas de açúcar e álcool na região, que poderá ocorrer ou não, doravante, no cenário regional.

\section{Nota}

1. O trabalho deriva de uma pesquisa de doutorado em Geografia finalizada em fevereiro de 2011 no Programa de Pós-Graduação em Geografia, da Faculdade de Ciências e Tecnologia - FCT/UNESP, campus de Presidente Prudente (SP), realizada pelo primeiro autor sob a orientação do segundo autor deste artigo.

\section{Referências}

ABRAMOVAY, R. Funções e medidas da ruralidade no desenvolvimento contemporâneo. Texto para discussão, n. 702. Rio de Janeiro: IPEA, 2000. 31 p.

BRANDÃO, C. A. Território e desenvolvimento: as múltiplas escalas entre o local e o global. Campinas: Editora UNICAMP, 2007.

CAMPANHOLA, C.; SILVA, J. G. da. Desenvolvimento local e a democratização dos espaços rurais. In: Cadernos de Ciência \& Tecnologia, Brasília, v. 17, n. 1, p. 11-40, jan./abr. 2000.

CARVALHO, Y. M. C. de; KUHN, V. L. Agricultura familiar no Estado de São Paulo: políticas e condições econômicas. Informações Econômicas, São Paulo, v. 29, n. 8, p. 15-48, 2001.

CLEMENTE, E. C. Formação, dinâmica e a reestruturação da cadeia produtiva do leite na região de Jales (SP). 183 f. Dissertação (Mestrado em Geografia) - FCT/ UNESP, Presidente Prudente (SP), 2006.

ELIAS, D. Agricultura e produção de espaços urbanos não metropolitanos: notas teórico-metodológicas. In: SPÓSITO, M. E. B. (Org.). Cidades médias: espaços em transição. São Paulo: Expressão Popular, 2007. p. 113-138.

FAVARETO, A. Paradigmas do desenvolvimento rural em questão. São Paulo: Iglu/ FAPESP, 2007. $220 \mathrm{p}$.

GUANZIROLI, C. E. Desenvolvimento territorial rural no Brasil: uma polêmica. In: Anais do XLVI SOBER, Rio Branco, 2008. (mimeo). 
KAGEYAMA, A. Desenvolvimento rural: conceitos e aplicações ao caso brasileiro. Porto Alegre: Editora UFRGS, Programa de Pós-Graduação em Desenvolvimento Rural, 2008.

LOCATEL, Celso Donizete. Modernização da agricultura, políticas públicas e ruralidade: mudanças e permanências na dinâmica rural das microrregiões de Jales e de Fernandópolis (SP). Tese (Doutorado em Geografia) - FCT/UNESP, Presidente Prudente, 2004.

NARDOQUE, S. Renda da terra e produção do espaço urbano em Jales (SP). 445 f. Tese (Doutorado em Geografia) - Instituto de Geociências e Ciências Exatas (IGCE), UNESP, Rio Claro, 2007.

OLIVEIRA, A. U. de. Geografia agrária: perspectivas no início do século XXI. In: OLIVEIRA, A. U. de; MARQUES, M. I. O campo no século XXI: território de vida, de luta e de construção da justiça social. São Paulo: Paz e Terra, 2003. p. 29-70.

SANTOS, M. Metamorfoses do espaço habitado: fundamentos teóricos e metodológicos da Geografia. 6. ed. São Paulo: Editora da Universidade de São Paulo, 2008. (original em 1988).

SARACENO, E. O conceito de ruralidade: problemas de definição em escala europeia. Trad. Ângela Kageyama. 1996. (mimeo).

SCHNEIDER, S.; TARTARUGA, I. G. P. Território e abordagem territorial: das referências cognitivas aos aportes aplicados à análise dos processos sociais rurais. Raízes: Revista de Ciências Sociais, Campina Grande (PB), v. 23, n. 1 e 2, p. 99117, 2004.

SILVA, J. G. da; DEL GROSSI, M.; CAMPANHOLA, C. O que há de realmente novo no rural brasileiro. Cadernos de Ciência \& Tecnologia, Brasília, v. 19, n. 1, p. 3767, 2002.

SMITH, N. Desenvolvimento desigual: natureza, capital e a produção do espaço. Trad. Eduardo de Almeida Navarro. Rio de Janeiro: Editora Bertrand Brasil, 1990.

VAN DER PLOEG et al. Rural development: from practices and policies towards theory. Sociologia Ruralis, Oxford, v. 40, n. 4, 2000.

VEIGA, J. E. da. A face territorial do desenvolvimento. Revista Internacional de Desenvolvimento Local, p. 5-19, set. 2002. Disponível em: http:/www.econ.fea. usp.br/zeeli/Textos/ArtigosCientificos/\%5B20\%5Dface_territorial.ht. Acesso em: 02 fev. 2008.

WANDERLEY, M. de N. B. A ruralidade no Brasil moderno. Por um pacto social pelo desenvolvimento rural. In: GIARRACA, N. (Org.). Uma nova ruralidade na América Latina?. Buenos Aires: Asdi/Clacso, 2001. p. 31-44. 
Evandro César Clemente - Graduado em Geografia pela Universidade Estadual Paulista Júlio de Mesquita Filho - Mestre e Doutor em Geografia pela mesma instituição - Professor dos cursos de Graduação e Pós-Graduação da Universidade Federal de Goiás, campus de Jataí.

Antonio Nivaldo Hespanhol - Graduado em Geografia pela Universidade Estadual Paulista Júlio de Mesquita Filho - Mestre e Doutor em Geografia pela mesma instituição - Pós-Doutor em Geografia - Professor da Universidade Estadual Paulista Júlio de Mesquita Filho.

Recebido para publicação em 23 de agosto de 2013

Aceito para publicação em 11 de novembro de 2013 